\title{
RON alternative splicing regulation in primary ovarian cancer
}

\author{
SEBASTIAN MAYER ${ }^{1}$, MARC HIRSCHFELD ${ }^{1-3}$, MARKUS JAEGER ${ }^{1}$, SUSANNE PIES ${ }^{1,4}$, \\ SEVERINE IBORRA $^{1}$, THALIA ERBES ${ }^{1}$ and ELMAR STICKELER ${ }^{1,2}$
${ }^{1}$ Department of Obstetrics and Gynecology, University Medical Center Freiburg, Freiburg; ${ }^{2}$ German Cancer Consortium for Translational Cancer Research (DKTK), Heidelberg; ${ }^{3}$ German Cancer Research Center (DKFZ), Heidelberg; ${ }^{4}$ Department of Nephrology, Klinikum rechts der Isar, Technische Universität München, Munich, Germany

Received February 24, 2015; Accepted March 30, 2015

DOI: 10.3892/or.2015.3995

\begin{abstract}
The proto-oncogene recepteur d'origine nantais (RON, MST1R) and its alternatively spliced variants are involved in various tumor biological processes, such as cell motility, adhesion, proliferation, apoptosis and epithelial-tomesenchymal transition (EMT). RON overexpression and the occurrence of specific alternatively spliced RON isoforms have been detected in ovarian cancer. In the present study, we evaluated the role and regulation of cancer-related RON splicing isoforms in primary ovarian cancer. Expression of RON variants (RON $\Delta 165$, RON $\Delta 160)$ was determined in 45 primary ovarian cancer and 4 physiological ovarian tissue specimens by RT-PCR and western blot analysis. The results were correlated to clinicopathological parameters. Additionally, expression of splicing factors with known involvement in RON alternative splicing regulation was examined. Increased RON levels were detected in all tumor samples $(\mathrm{P}=0.001)$ without differences between the primary tumors and metastases. Alternative RON variants were present in the majority of tumor samples (39 of $45 ; 86.67 \%)$. Potential RON $\Delta 165$ occurred more often $(82.22 \%)$ than potential RON $\Delta 160$ or RON $\Delta 155(24.40 \%)$. Several significant correlations of RON and splicing factor expression [e.g. ASF/SFRS1 $(\mathrm{P}=0.035)]$ were detected. Correlations of RON expression to clinicopathological parameters were not observed. Significant splicing factor interactions (e.g. SRp55/SRp75: $\mathrm{P}<0.001$ ) were observed in tumor samples with alternative RON splicing. Our data demonstrated upregulated RON isoform expression and significant changes in splicing factor expression in primary ovarian cancer. These findings account for an essential regulatory interplay of splicing factordriven alterations in the RON alternative splicing pattern with subsequent tumor biological consequences in ovarian cancer.
\end{abstract}

Correspondence to: Professor Elmar Stickeler, Department of Obstetrics and Gynecology, University Medical Center Freiburg, Hugstetter Strasse 55, D-79106 Freiburg, Germany

E-mail: elmar.stickeler@uniklinik-freiburg.de

Key words: RON, recepteur d'origine nantais, alternative splicing, primary ovarian cancer, splicing factor

\section{Introduction}

Regulation of gene expression is predominantly directed by alternative pre-mRNA splicing. A fine-tuned balance of factors is vital to the subtle distinction in the determination of splicing patterns with crucial biological consequences. Alterations in alternative splicing patterns result in functional changes in gene products and may account for both the cause or consequence of various human diseases (1). Cancer-associated changes in splicing processes accompanying the development and progression of malignant phenotypes have been identified in numerous studies $(2,3)$. Various pre-mRNAs originating from aberrant splicing most likely predispose cancer and are under consideration to serve as therapeutic targets (2), e.g. tumor suppressors (4), angiogenic factors (5-7) or apoptosis inhibitors $(8,9)$. Specific pre-mRNAs from alternatively spliced genes have been shown to contribute to acquisition of drug-resistant phenotypes in reaction to anticancer chemotherapies (10).

The proto-oncogene recepteur d'origine nantais (RON, MST1R) encodes a transmembrane tyrosine kinase receptor for macrophage-stimulating protein (MSP) and plays a crucial role in various tumor biological processes, such as cell motility, adhesion, proliferation, apoptosis and epithelial-to-mesenchymal transition (EMT) (11). The 185-kDa RON mature protein is characterized by a disulfide-linked extracellular $\alpha$ $(40 \mathrm{kDa})$ and a transmembrane $\beta$ chain $(145 \mathrm{kDa})$ and is organized in heterodimers with unique functional features of the MET protein family to control cell dissociation and invasion of extracellular matrices (scattering) $(12,13)$. The multifunctional factor is involved in several oncogenic pathways, such as PI-3 kinase/Akt, $\beta$-catenin, MAP kinase and JNK (14), where functional diversity originates from various alternative RON splice variants (13). In addition to mature RON, six isoforms emerging from alternative pre-mRNA splicing, protein truncation or alternative transcription start have been identified to date (Table I) (13,15).

Expression of alternative RON isoforms $\Delta 160$ and $\Delta 165$ are clearly correlated to tumor progression processes $(12,16-$ 18). Altered RON expression profiles represent an auspicious target for therapeutic approaches, such as chemical inhibitors or specific antibodies against cancer-associated RON protein variants (13). 
Table I. RON splicing isoforms and functional implications.

\begin{tabular}{|c|c|c|c|c|c|}
\hline $\begin{array}{l}\mathrm{RON} \\
\text { variant }\end{array}$ & Mechanism & $\begin{array}{l}\text { Tyrokinase } \\
\text { activity }\end{array}$ & $\begin{array}{l}\text { Cellular } \\
\text { localization }\end{array}$ & $\begin{array}{l}\text { Functional } \\
\text { implication }\end{array}$ & Refs. \\
\hline $\mathrm{RON} \Delta 170$ & $\begin{array}{l}\text { Splicing exon } 19 \\
\text { deletion }\end{array}$ & - & Membrane & $\begin{array}{l}\text { Inhibitor of oncogenic } \\
\text { activities }\end{array}$ & $(13,30)$ \\
\hline $\mathrm{RON} \Delta 165$ & $\begin{array}{l}\text { Splicing in-frame } \\
\text { deletion in exon } 11\end{array}$ & + & $\begin{array}{l}\text { Accumulation of single-chain } \\
\text { pro-RON } \Delta 165 \text { in cytoplasm }\end{array}$ & $\begin{array}{l}\text { Motile and invasive } \\
\text { phenotype }\end{array}$ & $(11-13,18,28,30,31)$ \\
\hline RON $\Delta 160$ & $\begin{array}{l}\text { Splicing in-frame } \\
\text { deletion in exon 5-6 }\end{array}$ & + & Membrane & $\begin{array}{l}\text { Tumor growth, increase } \\
\text { in } \beta \text {-catenin target gene } \\
\text { expression, metastasis }\end{array}$ & $(13,17,18,30-33)$ \\
\hline RON $\Delta 155$ & $\begin{array}{l}\text { Splicing combined } \\
\text { deletion of exons } \\
5,6 \text { and } 11\end{array}$ & + & Cytoplasm & $\begin{array}{l}\text { Tumor growth, } \\
\text { similarly to RON } \Delta 160\end{array}$ & $(13,18,30,31)$ \\
\hline RON $\Delta 110$ & $\begin{array}{l}\text { Proteolytic } \\
\text { truncation }\end{array}$ & + & Cell surface, cytoplasm & $\begin{array}{l}\text { RON-overexpressing } \\
\text { cancer cells, } \\
\text { tumorigenicity }\end{array}$ & $(13,30,33)$ \\
\hline $\mathrm{RON} \Delta 55$ & $\begin{array}{l}\text { Alternative } \\
\text { transcription start } \\
\text { in exon } 11\end{array}$ & + & Membrane, cytoplasm & $\begin{array}{l}\text { Cell transformation } \\
\text { and migration }\end{array}$ & $(13,30)$ \\
\hline
\end{tabular}

Ovarian cancer is diagnosed in 200,000 women every year worldwide. It accounts for $20 \%$ of all cancer-related deaths among women. In $~ 90 \%$ of cases, development of ovarian cancer is a sporadic event, in $10 \%$ there is a genetic disposition [breast and ovarian cancer syndrome (BOC) or Lynch II syndrome] (19). Malignant transformation in ovarian cancer is supported by several molecular changes such as upregulation of RTKs (receptor tyrosine kinases), mutation of tumor suppressor genes and increased activity of proteolytic enzymes.

Ferrandina and colleagues (20) investigated the prognostic relevance of RON protein expression levels in ovarian cancer patients by immunohistochemical analysis pointing out a specific significant link of platinum resistance and RON expression. The correlation of RON-associated chemoresistance against cisplatin was also shown in vitro (21).

Splicing factors belonging to the family of SR proteins (SRp20, SRp40, SRp55, SRp75 and ASF/SFRS1) and hTra2- $\beta 1$ play a crucial role in constitutive and alternative splicing and are involved in post-transcriptional processes such as mRNA nuclear export, nonsense-mediated decay and translation $(22,23)$. In breast cancer as well as in ovarian cancer a specific induction of different splicing factors has been observed $(24,25)$. YB-1 is a member of the family of coldshock proteins and acts as a splicing and transcription factor. In ovarian cancer, overexpression of YB-1 is associated with chemotherapy drug resistance and serves as a negative prognostic factor $(26,27)$.

The functional role of RON in ovarian carcinogenesis remains unclear. In the present study, we performed a targeted analysis of expression of specific RON variants in primary ovarian cancer and investigated its potential correlation to clinicopathological parameters. Since RON alternative splicing is governed by splicing factor activity $(13,28)$ we also performed correlative analysis of expression levels of several splicing factors with known involvement in RON mRNA processing.

\section{Materials and methods}

Patients and tissue samples. The present study is based on a multi-center cohort of 43 patients who received surgical treatment for primary epithelial ovarian cancer between 2003 and 2009. Tissues were sampled during primary surgery at the Departments of Obstetrics and Gynecology of the University Medical Center Freiburg, Charité Campus Virchow-Klinikum Berlin, Medical Center Bayreuth, University Medical Center Greifswald, University Medical Center Vienna and the Oncological Institute of Moldavia and stored at the Tumor Bank Ovarian Cancer (TOC). Specimens were freshly frozen in liquid nitrogen and immediately stored at $-80^{\circ} \mathrm{C}$ until further analysis. Clinicopathological parameters were documented in the TOC database including age, date of initial diagnosis and surgery, FIGO and TNM stage, grade, histological subtype, tissue sample localization, post-surgical therapies and follow-up data. Forty-five samples from 43 patients were collected and analyzed. Usually one tumor specimen was obtained from each patient (41 patients). In two patients 2 tumor samples of different origin (omentum majus/left ovary and omentum majus/uterus) were collected. In addition, 4 non-pathological ovarian tissue specimens were obtained at surgery performed at the Department of Obstetrics and Gynecology of the University Medical Center Freiburg and were histologically classified at the Institute of Pathology. All patients provided written consent and the study was approved by the Ethics Review Committee of the University Medical Center Freiburg, Germany, in accordance with human rights for patients in research. 
Table II. Characteristics of the ovarian cancer patients evaluated in the study $(\mathrm{N}=43)$.

\begin{tabular}{lrr}
\hline & No. of patients & Percentage $(\%)$ \\
\hline Age (years) & & \\
$<45$ & 7 & 16.3 \\
$45-60$ & 19 & 44.2 \\
$>60$ & 16 & 37.2 \\
N/O & 1 & 2.3 \\
FIGO stage & & \\
I & 9 & 20.9 \\
II & 3 & 7.0 \\
III & 24 & 55.8 \\
IV & 4 & 9.3 \\
N/O & 3 & 7.0 \\
Grade & & \\
1 & 6 & 14.0 \\
2 & 13 & 30.2 \\
3 & 17 & 39.5 \\
N/O & 7 & 16.3 \\
Histological subtype & & 9.3 \\
Serous & 33 & 46.7 \\
Mucinous & 4 & 9.3 \\
Others & 4 & \\
N/O & 2 & \\
\hline
\end{tabular}

Statistical analysis. The patient cohort ( $=43)$ was subgrouped for statistical analysis in regard to age, FIGO stage, TNM stage, histological subtype, grade, localization of tumor tissue sampling and resistance to platinum-derived chemotherapy (Table II). Statistical analysis was performed using SPSS software (version 20.0; SPSS, Inc., Chicago, IL, USA). Correlations were tested with the Spearman's correlation coefficient $\left(r_{S}\right)$ and the Mann-Whitney U test. A P-value $<0.05$ was considered to indicate a statistically significant result.

RNA isolation and PCR methods. Total RNA was isolated by TRIzol ${ }^{\circledR}$ reagent (Invitrogen ${ }^{\mathrm{TM}}$, Life Technologies ${ }^{\mathrm{TM}} \mathrm{GmbH}$, Thermo Fischer Scientific, Darmstadt, Germany) method according to the manufacturer's protocol after homogenization of tissue specimens by Ultra-Turrax ${ }^{\circledR}$ (IKA Werke, Staufen, Germany). RNA quality and quantity was determined by densitometry. Reverse transcription of $2 \mu \mathrm{g}$ purified RNA into cDNA was performed using MMLV-RT (Promega $\mathrm{GmbH}$, Mannheim, Germany), RiboLock RNase inhibitor (Fermentas $\mathrm{GmbH}$, Thermo Fischer Scientific, St. Leon-Roth, Germany), and random hexamer primers (New England BioLabs GmbH, Frankfurt, Germany) followed by either real-time PCR using QuantiFast SYBR-Green PCR Master Mix (Qiagen, Hilden, Germany) or conventional RT-PCR Taq polymerase (Genaxxon Bioscience GmbH, Ulm, Germany) and gene-specific primers. For best possible precision only singular PCR was performed. Isoforms with known oncologic potential, such as isoforms with exon 5 and 6 skip (potential RON $\Delta 165$ ) and exon 11 skip (potential RON $\Delta 160$ ) were investigated. A PCR spanning exons 4 to 12 was not performed since estimated amplicon sizes $(>1,000 \mathrm{bp})$ were too big for accurate separation. Expression levels of housekeeping gene RPS18 served as the comparative value. The sequence of primers and expected amplicon sizes were: for real-time PCR: RPS18-S, 5'-TAC TCA ACA CCA ACA TCG ATG GGC-3' and -AS, 5'-GCT TTC CTC AAC ACC ACA TGA GCA-3'; HIF-1 $\alpha-S, 5$ '-CGT TCC TTC GAT CAG TTG TC-3' and -AS, 5'-TCA GTG GTG GCA GTG GTA GT-3'; RON standard-S, 5'-TGA GGT CAA GGA TGT GCT GA-3' and -AS, 5'-GTG ACT TGA TGG CAC ATT GG-3'; SRp75-S, 5'-TAA GGG CTA CGG GAA GAT CC-3' and -AS: 5'-CCA CAA AGG TCT TTG CCA TT-3'; SRp55-S, 5'-GAC GGC TAC AGC TAC GGA AG-3' and -AS, 5'-CCA ACT GCA CCG ACT AGA AA-3'; SRp40-S, 5'-TCC AAG GGA TGC AGA TGA TGC TGT-3' and -AS, 5'-TAT CGT CCT CTA CCT CTT CCA CCT-3'; SRp20-S 5'-GAA GAC TCA TCG GAG CGT GT-3' and -AS, 5'-TGT TGC CAT TGT TTC CAA GA-3'; htra2- $\beta 1-S$, 5'-ATG ACC AGC AGT CTA GGC GTT CAA-3' and -AS, 5'-ATC CTA CGC CCA TCA AGC TCC ATT-3' and YB-1-S, 5'-TGG TTC AAT GTA AGG AAC GGA-3' and -AS, 5'-ACT GCG AAG GTA CTT CCT GG-3'; ASF/SF2-S, 5'-CGT GTT CTA CAA ATA CGG CG-3' and -AS, 5'-ACC CAT CGT AAT CAT AGC CG-3'; for RT-PCR: RON $\Delta 165$ (exon 11 skipping) S 5'-ACC TAG TTC CAC TGA AGC CT-3' and -AS, 5'-ACC AGT AGC TGA AGA CCA GT-3' (339 and 147 bp); RON $\Delta 160$ (exon 5-6 skipping) S, 5'-CAC TGC CCA CCT AAG CTT AC-3' and -AS, 5'-CTG GTG CCT ACA GAC AGA CT-3' (445, 285, 279 and $119 \mathrm{bp}$ ). RT-PCR products were subsequently analyzed by gel electrophoresis.

Protein isolation and western blot analysis. Protein isolation was performed in parallel to RNA extraction by TRIzol ${ }^{\circledR}$ reagent method according to the manufacturer's protocol after homogenization of tissue specimens by Ultra-Turrax ${ }^{\circledR}$. Protein concentrations were determined with the $\mathrm{BCA}^{\mathrm{TM}}$ protein assay kit (Pierce, Thermo Fischer Scientific, Rockford, IL, USA). Protein samples were separated by $10 \%$ SDS-PAGE and transferred onto polyvinylidene difluoride (PVDF) membranes (Carl Roth GmbH \& Co. KG, Karlsruhe, Germany) by using a Bio-Rad Trans-Blot Cell (Bio-Rad Laboratories GmbH, Munich, Germany). Membranes were soaked in blocking solution [phosphate-buffered saline (PBS) with 3\% dry non-fat milk, $0.1 \%$ Tween-20] for $1 \mathrm{~h}$ at room temperature and incubated with the primary polyclonal rabbit IgG antibody anti-RON $\beta$ (Santa Cruz Biotechnology, Inc., Santa Cruz, CA, USA; dilution 1:500) in blocking buffer overnight at $4^{\circ} \mathrm{C}$. After washing, the membranes were further incubated with horseradish peroxidase-conjugated goat anti-rabbit IgG secondary antibody (Jackson ImmunoResearch Europe Ltd., Suffolk, $\mathrm{UK}$; dilution 1:7,500) in blocking buffer for $2 \mathrm{~h}$ at room temperature. Finally the immunocomplexes were made visible by an enhanced chemiluminescence western blot detection kit (Pierce) and exposed to X-ray film (Fujifilm Europe GmbH, Düsseldorf, Germany).

\section{Results}

Expression of oncogenic RON variants in primary ovarian cancer. Forty-five tumor samples of primary ovarian cancer 


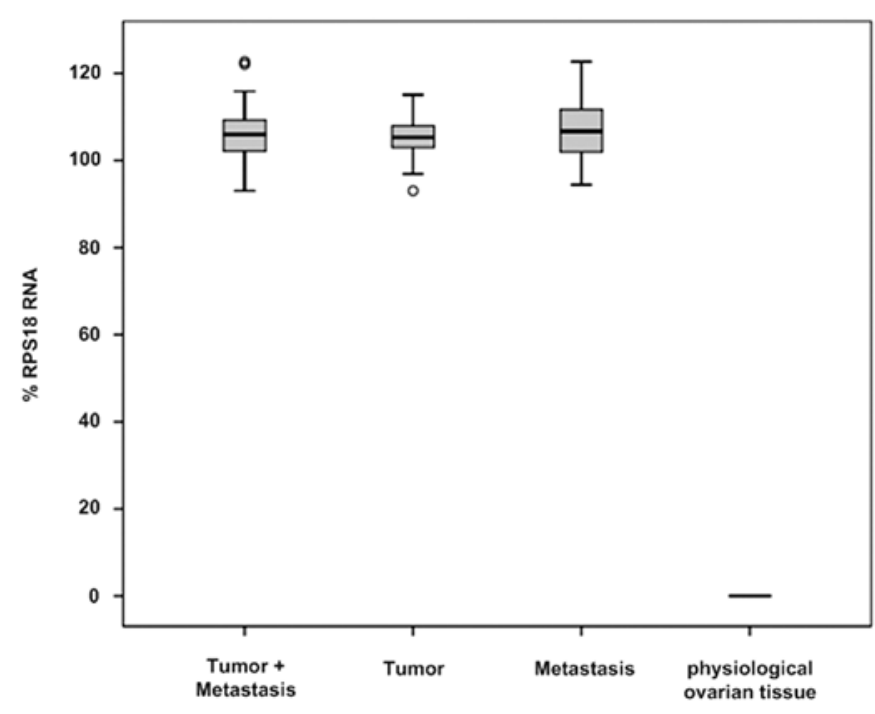

Figure 1. RON expression levels in malignant (primary and metastatic) and physiological ovarian tissues. RPS18 expression served as a comparative value in RT-PCR analysis.

and 4 non-pathological ovarian tissue samples were analyzed in regard to the expression profiles of total RON (all isoforms). In addition, the expression of the alternatively spliced RON isoforms with exon skip 5-6 (potential RON $\Delta 160$ and RON $\Delta 155$ ) and exon skip 11 (potential RON $\Delta 165$ ) bearing a known oncogenic potential was investigated in particular.

High levels of RON expression were detected in all 45 ovarian tumor tissues with statistical significance $(105.94 \pm 6.46$ vs. $0.00, \mathrm{P}=0.001)$. The origin of the tumor specimens $\mathrm{did}$ not influence the expression levels of RON; tissue samples of primary tumors $(\mathrm{N}=25)$ as well as metastases $(\mathrm{N}=20)$ showed high levels of RON expression $(105.29 \pm 5.45$ vs. $106.70 \pm 7.46$, $\mathrm{P}=0.337$ ). In contrast, all non-pathological (physiological) ovarian tissue samples $(\mathrm{N}=4)$ were characterized by no detectable RON expression (Fig. 1 and Table III). Alternative splicing of RON exon $5 / 6$ or exon 11 was noted in 39 of the 45 tumor samples $(86.67 \%)$ whereas 6 tumor samples showed no alternative splicing of RON (13.33\%). Notably, the non-pathological ovarian tissues did not express any RON mRNA variants.

RT-PCR analysis employing RON exon 4 to 7 spanning primers resulted in the detection of three different amplicons. Full length RON (445 bp) expression was found in most malignant ovarian tissues ( 39 of $45 ; 86.67 \%$ ). The expected potential RON $\Delta 160$ or RON $\Delta 155$ mRNA (119 bp), characterized by exclusion of exon cassette 5-6, was observed in a fraction of tumor samples only (11 of $45 ; 24.40 \%$ ). The third RT-RCR amplicon with estimated $280 \mathrm{bp}$ was detected at a higher frequency in the ovarian cancer tissue specimens (29 of 45; $64.44 \%$ ). This RON mRNA could have been either characterized by solitary exon 5 (284 bp) or exon 6 exclusion (297 bp), whereas subsequent sequence analysis clearly identified the exon 5 skipping mRNA variant (284 bp) (Fig. 2A). In the metastatic tissues, expression of RON mRNA variants with exclusion of exon cassette 5-6 was more frequent than that in the primary tumors (35 vs. $16 \%$ ), whereas in the primary tumor samples, expression of the exon 5 skipping mRNA variant (285 bp) was observed more often (76 vs. 50\%).
Table III. RON expression in physiological ovary, primary ovarian cancer tumor and metastatic tissues.

\begin{tabular}{lrrrr}
\hline & N & $\begin{array}{c}\text { RON standard } \\
(\text { median })\end{array}$ & SD & P-value \\
\hline Tumor & 25 & 105.29 & 5.45 & \\
Metastasis & 20 & 106.70 & 7.46 & 0.337 \\
Tumor & 25 & 105.29 & 5.45 & \\
Normal tissue & 4 & 0.00 & 0.00 & $\mathbf{0 . 0 0 2}$ \\
Metastasis & 20 & 106.70 & 7.46 & \\
Normal tissue & 4 & 0.00 & 0.00 & $\mathbf{0 . 0 0 2}$ \\
Tumor/metastasis & 45 & 105.94 & 6.46 & \\
Normal tissue & 4 & 0.00 & 0.00 & $\mathbf{0 . 0 0 1}$ \\
\hline
\end{tabular}

$\mathrm{SD}$, standard deviation.

Expression analysis of RON variants with exon 11 skipping (potential RON $\Delta 165$ ) via RT-PCR was performed using RON exon 10 to 12 spanning primers and resulted in the detection of conventionally spliced RON including exon 11 (339 bp) as well as an exon 11-skipping RON variant (192 bp) with varying intensity in the majority of the ovarian tumor tissues (37 of $45 ; 82.22 \%$ ). In the metastatic tissues, expression of RON variants with exclusion of exon 11 was more frequent than that in the primary tumor tissues (90 vs. 76\%). Additionally, another amplicon (509 bp) occurred in almost all analyzed malignant tissues (44 of $45 ; 97.78 \%$ ). This mRNA originated from intron 10-11 and intron 11-12 retention. Sequencing analysis revealed that this PCR product does not encode for a biologically active protein, since premature termination codons (PTCs) are introduced (Fig. 2B). PTCs most likely constitute RNA degradation via nonsense-mediated decay.

Quantitative RON protein expression analysis (western blot analysis) employed a specific antibody directed against the C-terminus of RON. Non-pathological ovarian tissues showed expression of two RON protein isoforms only, in fact unprocessed pre-RON (190 kDa) and 'short form RON' (RON $\Delta 55$ with $55 \mathrm{kDa}$ ). Ovarian tumor specimens also expressed pre-RON and RON $\Delta 55$, plus a variety of additional protein isoforms, e.g. RON $\Delta 155$ (125 kDa $\beta$-chain), RON $\Delta 160$ (135 kDa, $\beta$-chain), RON $\Delta 165$ (165 kDa, single chain) (data not shown). Only slightly differing molecular weights of the different isoforms made a precise quantification impossible.

In the ovarian tumor samples, a significant correlation between total RON splicing and the expression of splicing factors ASF/SFRS1 ( $\mathrm{P}=0.035), \mathrm{SRp} 40(\mathrm{P}=0.015), \mathrm{SRp} 55$ $(\mathrm{P}=0.015)$ and SRp75 $(\mathrm{P}=0.039)$ was detected. More detailed analysis comparing tumor samples with alternative splicing of RON exon $5 / 6$ or exon $11(\mathrm{~N}=39)$ to tumor samples without alternative splicing of RON exon $5 / 6$ or exon $11(\mathrm{~N}=6)$ revealed different correlations to splicing factor expression. While tumor samples with alternative splicing events of RON were characterized by significant correlations of RON expression and the expression of certain splicing factors (SRp40, $\mathrm{P}=0.047$; SRp55, $\mathrm{P}=0.005$; SRp75, $\mathrm{P}=0.019$ ), no significant correlations 
A

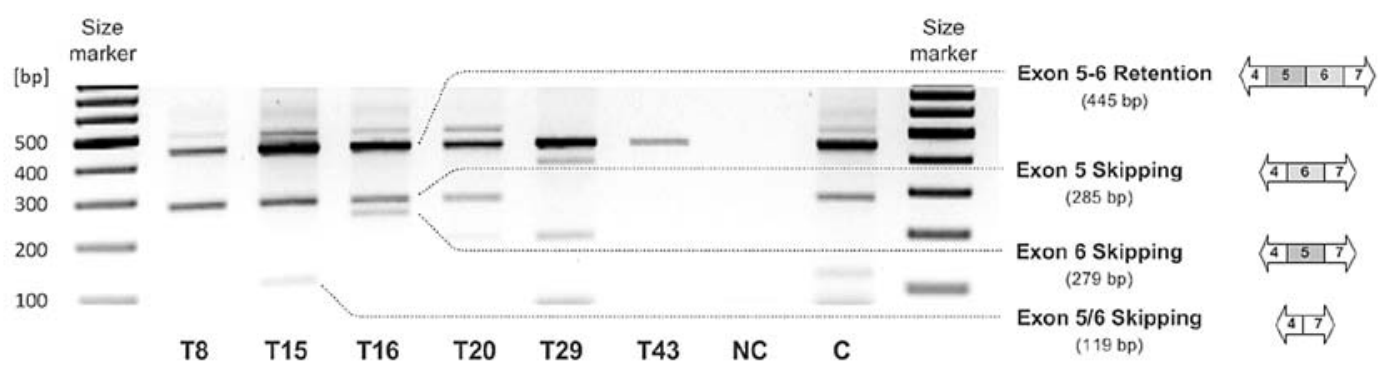

B

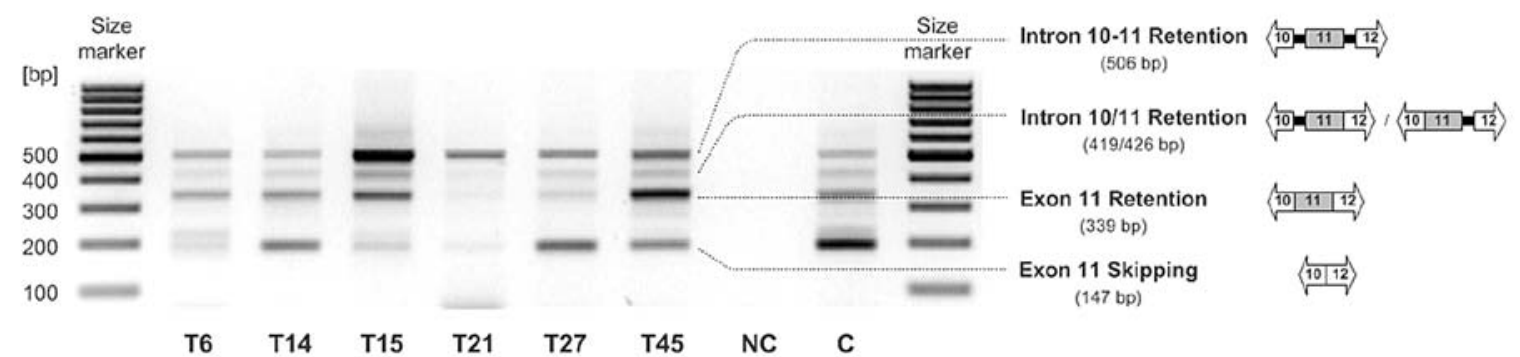

Figure 2. RON mRNA expression profiles in regard to (A) exon 5/6 skipping isoforms and (B) exon 11 skipping and intron 10/11 retaining isoforms in 6 different ovarian cancer tissue specimens ( $\mathrm{T})$, negative control $\left(\mathrm{NC}, \mathrm{H}_{2} \mathrm{O}\right)$ and positive control (C, Ishikawa cells). Scheme of the splicing isoform structures are indicated at the right. RT-PCR with primer (A) RON $\Delta 160$ (exon 5-6 skipping) or with primer (B) RON $\Delta 165$ (exon 11 skipping).

Table IV. RON and splicing factor expression.

\begin{tabular}{lccccc}
\hline $\begin{array}{l}\text { RON } \\
\text { expression }\end{array}$ & $\begin{array}{c}\text { All tumor samples } \\
(\mathrm{N}=45)\end{array}$ & $\begin{array}{c}\text { Alternative RON } \\
\text { splicing }(\mathrm{N}=39)\end{array}$ & $\begin{array}{c}\text { No alternative } \\
\text { RON splicing }(\mathrm{N}=6)\end{array}$ & $\begin{array}{c}\text { Alternative splicing } \\
\text { Exon 11 }(\mathrm{N}=37)\end{array}$ & $\begin{array}{c}\text { Alternative splicing } \\
\text { Exon 5/6 }(\mathrm{N}=11)\end{array}$ \\
\hline ASF/SFRS1 & $\mathbf{0 . 0 3 5}$ & $\mathbf{0 . 0 7 4}$ & 0.544 & $\mathbf{0 . 0 7 0}$ & 0.555 \\
SRp20 & 0.648 & 0.385 & 0.266 & 0.488 & 0.401 \\
SRp40 & $\mathbf{0 . 0 1 5}$ & $\mathbf{0 . 0 4 7}$ & $\mathbf{0 . 0 0 5}$ & $\mathbf{0 . 0 3 3}$ & 0.979 \\
SRp55 & $\mathbf{0 . 0 1 5}$ & $\mathbf{0 . 0 0 5}$ & 0.623 & $\mathbf{0 . 0 0 5}$ & 0.689 \\
SRp75 & $\mathbf{0 . 0 3 9}$ & $\mathbf{0 . 0 1 9}$ & 0.872 & $\mathbf{0 . 0 2 8}$ & 0.537 \\
Tra2B & 0.979 & 0.793 & 0.397 & 0.984 & 0.370 \\
YB-1 & 0.119 & 0.090 & 0.872 & 0.119 & 0.631 \\
\hline
\end{tabular}

Table V. Correlation of RON expression to clinicopathological parameters.

\begin{tabular}{lccccccc}
\hline $\begin{array}{l}\text { RON } \\
\text { expression }\end{array}$ & $\begin{array}{c}\text { All tumor } \\
\text { samples } \\
(\mathrm{N}=45)\end{array}$ & $\begin{array}{c}\text { Primary } \\
\text { tumor } \\
(\mathrm{N}=25)\end{array}$ & $\begin{array}{c}\text { Metastasis } \\
(\mathrm{N}=20)\end{array}$ & $\begin{array}{c}\text { Alternative } \\
\text { RON splicing } \\
(\mathrm{N}=39)\end{array}$ & $\begin{array}{c}\text { No alternative } \\
\text { RON splicing } \\
(\mathrm{N}=6)\end{array}$ & $\begin{array}{c}\text { Alternative splicing } \\
\text { Exon 11 } \\
(\mathrm{N}=37)\end{array}$ & $\begin{array}{c}\text { Alternative splicing } \\
\text { Exon 5/6 } \\
(\mathrm{N}=11)\end{array}$ \\
\hline Age & 0.205 & 0.141 & 0.972 & 0.247 & 0.544 & 0.320 & 0.331 \\
FIGO stage & 0.663 & 0.728 & 0.242 & 0.560 & 0.864 & 0.321 & 0.766 \\
Grade & 0.579 & 0.217 & 0.043 & 0.638 & 0.638 & 0.506 & 0.689 \\
Histology & 0.489 & 0.799 & 0.446 & 0.721 & 0.158 & 0.670 & 0.915 \\
Platin resistance & 0.638 & 0.586 & 0.158 & 0.312 & & 0.312 & 0.846 \\
FIGO/grading & $\mathbf{0 . 0 1 4}$ & $\mathbf{0 . 0 3 0}$ & 0.611 & $\mathbf{0 . 0 3 1}$ & 0.239 & $\mathbf{0 . 0 1 0}$ & $\mathbf{0 . 0 2 8}$ \\
FIGO/platin & $\mathbf{0 . 0 3 4}$ & 0.063 & 0.704 & $\mathbf{0 . 0 2 8}$ & & & \\
\hline
\end{tabular}

in tumor samples lacking RON alternative splicing were found, except for SRp40 ( $\mathrm{P}=0.005)$. Notably, tumor tissues with alternative splicing of exon $5 / 6$ (potential RON $\Delta 160, \mathrm{~N}=11$ ) showed no correlation of RON expression to splicing factors.
In contrast, in the tumor samples with alternative splicing of exon 11 (potential RON $\Delta 165, \mathrm{~N}=37$ ), significant correlations of RON expression to SRp40 ( $\mathrm{P}=0.033)$, SRp55 $(\mathrm{P}=0.05)$ and SRp75 $(\mathrm{P}=0.028)$ were determined (Table IV). 
Table VI. Expression of splicing factors in the physiological ovarian and ovarian cancer tissues.

\begin{tabular}{lccc}
\hline & $\begin{array}{c}\text { Tumor } \\
(\mathrm{N}=45)\end{array}$ & $\begin{array}{c}\text { Physiological } \\
(\mathrm{N}=4)\end{array}$ & P-value \\
\hline ASF/SFRS1 & $98.82 \pm 3.20$ & 0.00 & $\mathbf{0 . 0 0 1}$ \\
htra2- $\beta 1$ & $117.35 \pm 3.82$ & 0.00 & $\mathbf{0 . 0 0 1}$ \\
YB-1 & $114.51 \pm 5.02$ & $100.50 \pm 2.50$ & $\mathbf{0 . 0 0 1}$ \\
SRp20 & $115.26 \pm 7.66$ & $95.00 \pm 1.26$ & $\mathbf{0 . 0 0 1}$ \\
SRp40 & $110.38 \pm 4.25$ & $107.50 \pm 1.71$ & $\mathbf{0 . 0 2 4}$ \\
SRp55 & $123.21 \pm 3.55$ & $73.00 \pm 2.28$ & $\mathbf{0 . 0 0 1}$ \\
SRp75 & $122.26 \pm 4.51$ & $91.00 \pm 1.82$ & $\mathbf{0 . 0 0 1}$ \\
\hline
\end{tabular}

Correlation of RON expression to molecular and clinicopathological features. A significant correlation of FIGO stage and grade $(\mathrm{P}=0.014)$ as well as of FIGO stage and platin-resistance $(\mathrm{P}=0.034)$ was observed in the tumor samples in general. Corresponding results were observed in the tumor samples with RON alternative splicing events (FIGO stage/grading, $\mathrm{P}=0.031$; FIGO-stage/platinum-resistance, $\mathrm{P}=0.028$ ). Tumor samples without alternative splicing of RON showed no correlations to the clinicopathological parameters.

Significant correlations of RON expression and clinicopathological parameters such as age, FIGO stage, grade, histological subtype or resistance to platinum-derived chemotherapy were not detected in the analyzed tumor samples in general as well as in any subgroup (e.g. tumor samples with RON alternative splicing) (Table V). An exceptional signifi- cant correlation of RON expression with grade $(\mathrm{P}=0.043)$ was found in the metastatic issues.

Expression of splicing factors in the ovarian tumor specimens. To elucidate the potential role of intrinsic splicing factors within malignant cells, we investigated the expression patterns of those factors, known to be involved in the regulation of RON mRNA processing.

Expression levels of splicing factors ASF/SFRS1, htra2- $\beta 1$, YB-1, SRp20, SRp40, SRp55 and SRp75 were evaluated in the ovarian tumor samples $(\mathrm{N}=45)$ and non-pathological ovarian tissue specimens $(\mathrm{N}=4)$ by real-time-RT-PCR analysis. In comparison to the non-pathological tissues, the expression of all investigated splicing factors showed a significant upregulation in the ovarian tumor samples (Table VI).

Except for SRp20 (118.00 \pm 7.86 vs. $113.75 \pm 6.72, \mathrm{P}=0.027)$ no difference in expression levels of the splicing factors in the primary tumor samples $(\mathrm{N}=25)$ vs. metastases $(\mathrm{N}=20)$ were evident

In tumor samples with alternative RON splicing various significant splicing factor interactions were observed (e.g. SRp55/SRp75; $\mathrm{P}<0.001)$. Notably, this phenomenon was not detected in the tumor samples lacking RON alternative splicing (Table VII).

Statistical correlation analysis in regard to splicing factor expression and clinicopathological features showed a significant correlation of YB-1 ( $\mathrm{P}<0.001), \mathrm{SRp} 40(\mathrm{P}=0.046)$, SRp55 $(\mathrm{P}=0.002)$ and $\mathrm{SRp} 75(\mathrm{P}=0.002)$ with FIGO stage I and II $(\mathrm{N}=12)$ compared to FIGO stage III and IV $(\mathrm{N}=30)$. YB-1 also showed a significant correlation to platinum resistance $(\mathrm{P}=0.042)$. Other significant correlations of splicing factor expression and clinicopathological parameters such as age, grade or histologic subtype were not observed.

Table VII. Expression of splicing factors in ovarian cancer.

\begin{tabular}{|c|c|c|c|c|c|c|c|}
\hline & & ASF/SFRS 1 & SRp20 & SRp40 & SRp55 & SRp75 & $\operatorname{Tr} 2 \beta$ \\
\hline \multirow[t]{6}{*}{ All tumor samples } & SRp20 & 0.691 & & & & & \\
\hline & SRp40 & 0.064 & $\mathbf{0 . 0 3 7}$ & & & & \\
\hline & SRp55 & 0.002 & 0.489 & 0.000 & & & \\
\hline & SRp75 & 0.291 & 0.235 & 0.000 & 0.000 & & \\
\hline & $\operatorname{Tra} 2 \beta$ & 0.166 & 0.000 & 0.004 & 0.198 & 0.039 & \\
\hline & YB-1 & 0.413 & 0.411 & 0.000 & 0.000 & 0.000 & 0.049 \\
\hline \multirow{6}{*}{$\begin{array}{l}\text { With alternative } \\
\text { splicing }\end{array}$} & SRp20 & 0.501 & & & & & \\
\hline & SRp40 & 0.077 & 0.194 & & & & \\
\hline & SRp55 & 0.000 & 0.886 & 0.000 & & & \\
\hline & SRp75 & 0.165 & 0.194 & 0.000 & 0.000 & & \\
\hline & $\operatorname{Tra} 2 \beta$ & 0.290 & 0.000 & 0.015 & 0.152 & 0.013 & \\
\hline & YB-1 & 0.165 & 0.376 & 0.000 & 0.000 & 0.000 & 0.027 \\
\hline \multirow{6}{*}{$\begin{array}{l}\text { Without alternative } \\
\text { splicing }\end{array}$} & SRp20 & 0.787 & & & & & \\
\hline & SRp40 & 0.704 & 0.208 & & & & \\
\hline & SRp55 & 0.156 & 0.397 & 0.787 & & & \\
\hline & SRp75 & 0.623 & 0.623 & 0.704 & 0.544 & & \\
\hline & $\operatorname{Tra} 2 \beta$ & 0.208 & 0.397 & 0.266 & 0.468 & 0.468 & \\
\hline & YB-1 & 0.072 & 0.872 & 0.872 & 0.787 & 0.468 & 0.544 \\
\hline
\end{tabular}




\section{Discussion}

RON and its splice variants play an important role in various tumor biological processes such as cell motility, adhesion, proliferation, apoptosis and epithelial-to-mesenchymal transition (EMT) (11). In the present study, we analyzed the expression of RON and specific alternatively spliced RON variants with known oncologic potential in ovarian cancer tumor samples. In addition, the expression levels of splicing factors which are involved in the regulation of alternative splicing of RON were investigated.

In all of the ovarian tumor samples $(\mathrm{N}=45)$, high levels of RON expression were detected, whereas in the non-pathological ovarian tissues $(\mathrm{N}=4) \mathrm{RON}$ expression was absent $(\mathrm{P}=0.001)$. This observation supports the findings of Maggiora et al (29) who described overexpression of RON in ovarian carcinomas but only rarely detectable RON expression in normal ovarian tissue. There was no difference in RON expression regarding the origin of the sample (primary tumor vs. metastasis). Alternatively spliced RON variants with exclusion of exon 11 (potential RON $\Delta 165$ ) were present in the majority of the analyzed tumor samples $(82.22 \%)$ whereas the alternatively spliced RON variant with exclusion of exon $5 / 6$ (potential RON $\Delta 160$ or RON $\Delta 155$ ) was detectable in $24.40 \%$ of the tumor samples only. Expression of alternatively spliced RON variants was more frequent in metastases than in the primary tumors (exon 5/6 skip, 35 vs. 16\%; exon 11 skip, 90 vs. $76 \%$ ). The findings at the mRNA level were confirmed by western blot analysis at the protein level. While the non-pathological ovarian tissues only demonstrated pre-RON and RON $\Delta 55$ expression, ovarian cancer specimens expressed a variety of RON isoforms (including pre-RON, RON $\Delta 55, \mathrm{RON} \Delta 160$ and RON $\Delta 165)$.

Since alternatively spliced RON variants with exclusion of exon 11 (potential RON $\Delta 165$ ) are present more often in ovarian tumor samples than other alternatively spliced RON variants, these isoforms may play a more important role in ovarian cancer development and progression than others. Elevated expression levels of alternatively spliced RON isoforms in metastases in comparison to primary tumors might indicate that alterations in RON mRNA processing not only occur during tumor development, but are most likely an accompanying phenomenon in gradational ovarian cancer progression. Significant correlations of RON mRNA expression (neither overall RON expression nor expression of the investigated alternatively spliced RON variants) to clinicopathological parameters such as FIGO stage, grade or platinum resistance were not found in the present study. These findings are consistent for the most part with an immunohistochemical study of Ferrandina et al (20), who observed no correlations of RON expression to age, FIGO stage and histology. In the present study significant correlations were found for grade 3 and higher incidence of immunohistochemical RON expression as well as a significant inverse correlation of RON expression and survival in the subgroup of patients with platinum-resistant ovarian cancer recurrence.

To elucidate the role of intrinsic splicing factors in alternative splicing in ovarian cancer, we also analyzed the expression of splicing factors known to be involved in RON mRNA processing.
All investigated splicing factors ASF/SFRS1, htra2- $\beta 1$, YB-1, SRp20, SRp40, SRp55 and SRp75 showed a significant upregulation in the ovarian cancer samples when compared to the non-pathological ovarian tissues. Except for SRp20, no differences in splicing factor expression were noted in the primary tumors and metastases. Significant correlations of RON expression and splicing factors were noted in the ovarian cancer samples in general as well as in samples with known alternative splicing events of RON. These groups could also be characterized by significant interactions of splicing factors. In contrast in the tumor specimens without alternatively spliced RON mRNA neither correlations of RON to splicing factor expression nor significant splicing factor interactions were observed. These findings emphasize the crucial role of the investigated splicing factors for RON mRNA processing. Notably, alternative splicing of RON exon 5/6 does not appear to be regulated by the investigated splicing factors since there were no correlations observed for RON expression and splicing factor expression in the tumor samples exhibiting alternative exon $5 / 6$ splicing.

Several splicing factors were correlated to FIGO stage. A significant inverse correlation of YB-1, SRp40, SRp55 and SRp75 to FIGO stage I and II vs. FIGO stage III and IV was found in the present study. YB-1 was also correlated to platinum-resistance. These findings are consistent with other previously published studies $(26,27)$.

In conclusion, our findings account for an essential regulatory interplay of splicing factor-driven alterations in the RON alternative splicing pattern with subsequent tumor biological consequences in the development and progression of ovarian cancer. To the best of our knowledge, this is the first study describing significant changes in splicing factor expression in the regulation of RON alternative splicing in ovarian cancer patients. The observed essential interplay of different splicing factors in the mRNA processing of RON in ovarian cancer might extend the options for new therapeutic approaches not only to alternatively spliced RON isoforms but also to the involved regulatory splicing factors.

\section{References}

1. Skotheim RI and Nees M: Alternative splicing in cancer: Noise, functional, or systematic? Int J Biochem Cell Biol 39: 1432-1449, 2007.

2. Tazi J, Bakkour $\mathrm{N}$ and Stamm S: Alternative splicing and disease. Biochim Biophys Acta 1792: 14-26, 2009.

3. Venables JP: Unbalanced alternative splicing and its significance in cancer. BioEssays 28: 378-386, 2006.

4. Huiping C, Kristjansdottir S, Bergthorsson JT, Jonasson JG, Magnusson J, Egilsson V and Ingvarsson S: High frequency of LOH, MSI and abnormal expression of FHIT in gastric cancer. Eur J Cancer 38: 728-735, 2002.

5. Cheung N, Wong MP, Yuen ST, Leung SY and Chung LP: Tissuespecific expression pattern of vascular endothelial growth factor isoforms in the malignant transformation of lung and colon. Hum Pathol 29: 910-914, 1998.

6. Elias AP and Dias S: Microenvironment changes (in $\mathrm{pH}$ ) affect VEGF alternative splicing. Cancer Microenviron 1: 131-139, 2008.

7. Hirschfeld M, Jaeger M, Buratti E, Stuani C, Grueneisen J, Gitsch $\mathrm{G}$ and Stickeler E: Expression of tumor-promoting Cyr61 is regulated by hTRA2-2401 and acidosis. Hum Mol Genet 20: 2356-2365, 2011.

8. Krieg A, Mahotka C, Krieg T, Grabsch H, Müller W, Takeno S, Suschek CV, Heydthausen M, Gabbert HE and Gerharz CD: Expression of different survivin variants in gastric carcinomas: First clues to a role of survivin-2B in tumour progression. Br J Cancer 86: 737-743, 2002. 
9. Vegran F, Boidot R, Oudin C, Riedinger JM and Lizard-Nacol S Distinct expression of Survivin splice variants in breast carcinomas. Int J Oncol 27: 1151-1157, 2005.

10. Eblen ST: Regulation of chemoresistance via alternative messenger RNA splicing. Biochem Pharmacol 83: 1063-1072, 2012.

11. Ghigna C, De Toledo M, Bonomi S, Valacca C, Gallo S, Apicella M, Eperon I, Tazi J and Biamonti G: Pro-metastatic splicing of Ron proto-oncogene mRNA can be reversed: Therapeutic potential of bifunctional oligonucleotides and indole derivatives. RNA Biol 7: 495-503, 2010.

12. Collesi C, Santoro MM, Gaudino G and Comoglio PM: A splicing variant of the RON transcript induces constitutive tyrosine kinase activity and an invasive phenotype. Mol Cell Biol 16: 5518-5526, 1996.

13. Lu Y, Yao HP and Wang MH: Multiple variants of the RON receptor tyrosine kinase: Biochemical properties, tumorigenic activities, and potential drug targets. Cancer Lett 257: 157-164, 2007.

14. Danilkovitch-Miagkova A: Oncogenic signaling pathways activated by RON receptor tyrosine kinase. Curr Cancer Drug Targets 3: 31-40, 2003.

15. Wang MH, Wang D and Chen YQ: Oncogenic and invasive potentials of human macrophage-stimulating protein receptor, the RON receptor tyrosine kinase. Carcinogenesis 24: 1291-1300, 2003.

16. Wang MH, Kurtz AL and Chen Y: Identification of a novel splicing product of the RON receptor tyrosine kinase in human colorectal carcinoma cells. Carcinogenesis 21: 1507-1512, 2000.

17. Xu XM, Zhou YQ and Wang MH: Mechanisms of cytoplasmic $\beta$-catenin accumulation and its involvement in tumorigenic activities mediated by oncogenic splicing variant of the receptor originated from Nantes tyrosine kinase. J Biol Chem 280 : 25087-25094, 2005.

18. Zhou YQ, He C, Chen YQ, Wang D and Wang MH: Altered expression of the RON receptor tyrosine kinase in primary human colorectal adenocarcinomas: Generation of different splicing RON variants and their oncogenic potential. Oncogene 22: 186-197, 2003

19. Lynch HT, Casey MJ, Lynch J, White TE and Godwin AK: Genetics and ovarian carcinoma. Semin Oncol 25: 265-280, 1998.

20. Ferrandina G, Martinelli E, Petrillo M, Prisco MG, Zucconi A, Santaguida S, Zannoni G, Scambia G and Ferlini C: Prognostic role of the recepteur d'origine nantais (RON) expression in ovarian cancer patients. Gynecol Oncol 111: 237-243, 2008.
21. Prislei S, Mariani M, Raspaglio G, Mozzetti S, Filippetti F, Ferrandina G, Scambia G and Ferlini C: RON and cisplatin resistance in ovarian cancer cell lines. Oncol Res 19: 13-22, 2010.

22. Huang Y and Steitz JA: SRprises along a messenger's journey. Mol Cell 17: 613-615, 2005.

23. Zahler AM, Lane WS, Stolk JA and Roth MB: SR proteins: A conserved family of pre-mRNA splicing factors. Genes Dev 6: 837-847, 1992.

24. Fischer DC, Noack K, Runnebaum IB, Watermann DO, Kieback DG, Stamm S and Stickeler E: Expression of splicing factors in human ovarian cancer. Oncol Rep 11: 1085-1090, 2004.

25. Stickeler E, Kittrell F, Medina D and Berget SM: Stage-specific changes in SR splicing factors and alternative splicing in mammary tumorigenesis. Oncogene 18: 3574-3582, 1999.

26. Fujii T, Seki N, Namoto-Matsubayashi R, Takahashi H, Inoue Y, Toh U, Kage M and Shirouzu K: YB-1 prevents apoptosis via the mTOR/STAT3 pathway in HER-2-overexpressing breast cancer cells. Future Oncol 5: 153-156, 2009.

27. Kamura T, Yahata H, Amada S, Ogawa S, Sonoda T, Kobayashi H, Mitsumoto M, Kohno K, Kuwano M and Nakano H: Is nuclear expression of $\mathrm{Y}$ box-binding protein-1 a new prognostic factor in ovarian serous adenocarcinoma? Cancer 85: 2450-2454, 1999.

28. Ghigna C, Giordano S, Shen H, Benvenuto F, Castiglioni F, Comoglio PM, Green MR, Riva S and Biamonti G: Cell motility is controlled by SF2/ASF through alternative splicing of the Ron protooncogene. Mol Cell 20: 881-890, 2005.

29. Maggiora P, Lorenzato A, Fracchioli S, Costa B, Castagnaro M, Arisio R, Katsaros D, Massobrio M, Comoglio PM and Flavia Di Renzo M: The RON and MET oncogenes are co-expressed in human ovarian carcinomas and cooperate in activating invasiveness. Exp Cell Res 288: 382-389, 2003.

30. Wang MH, Yao HP and Zhou YQ: Oncogenesis of RON receptor tyrosine kinase: A molecular target for malignant epithelial cancers. Acta Pharmacol Sin 27: 641-650, 2006.

31. Camp ER, Liu W, Fan F, Yang A, Somcio R and Ellis LM: RON, a tyrosine kinase receptor involved in tumor progression and metastasis. Ann Surg Oncol 12: 273-281, 2005.

32. Chen YQ, Zhou YQ, Angeloni D, Kurtz AL, Qiang XZ and Wang MH: Overexpression and activation of the RON receptor tyrosine kinase in a panel of human colorectal carcinoma cell lines. Exp Cell Res 261: 229-238, 2000.

33. Ma Q, Zhang K, Guin S, Zhou YQ and Wang MH: Deletion or insertion in the first immunoglobulin-plexin-transcription (IPT) domain differentially regulates expression and tumorigenic activities of RON receptor tyrosine kinase. Mol Cancer 9: 307, 2010. 